\title{
A pharmacodynamic comparison of 5 anti-platelet protocols in patients with ST-elevation myocardial infarction undergoing primary $\mathrm{PCl}$
}

Sasha Koul ${ }^{1 *}$, Pontus Andell ${ }^{1}$ Andreas Martinsson ${ }^{1}$, J Gustav Smith, Fredrik Scherstén ${ }^{1}$, Jan Harnek , Matthias Götberg ${ }^{1}$, Eva Norström², Sven Björnsson ${ }^{2}$ and David Erlinge ${ }^{1}$

\begin{abstract}
Background: Despite advances in anti-platelet treatments, there still exists an early increase in both ischemic as well as bleeding events following primary PCI in patients with ST-elevation myocardial infarction (STEMI). Platelet inhibition data of different anti-platelet treatments in the acute phase of a myocardial infarction might offer some insight into these problems. The aim of this study was to evaluate the pharmacodynamic profile of 5 different anti-platelet treatments in the acute phase of STEMI in patients undergoing primary PCl.

Methods: A total of 223 STEMI patients undergoing primary PCI were prospectively included. Patients received either pre-hospital clopidogrel only, pre-hospital clopidogrel followed by prasugrel switch in the cath lab, prasugrel treatment only, pre-hospital clopidogrel followed by ticagrelor switch in the cath lab or pre-hospital ticagrelor only. Platelet reactivity was measured serially using vasodilator-stimulated phosphoprotein (VASP).

Results: Patients receiving pre-hospital clopidogrel followed by prasugrel switch showed similar platelet inhibition data as patients receiving prasugrel only, with more than $90 \%$ being good responders the day after PCl. Average time from prasugrel administration to a VASP value of $<50 \%$ was 1.5 hours. In patients receiving pre-hospital ticagrelor, $50 \%$ were good responders at completion of $\mathrm{PCl}$ and average time to a VASP-value of $<50 \%$ was 2.3 hours. Only $32 \%$ of patients receiving clopidogrel only were responders the day after $\mathrm{PCl}$.
\end{abstract}

Conclusions: Switching from an upstream bolus dose of clopidogrel to prasugrel the time of $\mathrm{PCl}$, appeared as a safe and feasible option with no tendency for overshoot or attenuation of platelet inhibition. Pre-hospital administration of ticagrelor was associated with a $50 \%$ good responder rate at completion of PCl.

Keywords: Prasugrel, Ticagrelor, Clopidogrel, Upstream, STEMI

\section{Background}

Usage of P2Y12-inhibitors constitutes a cornerstone in the treatment of acute coronary syndromes, including patients with ST-elevation myocardial infarction (STEMI) [1-3]. Despite modern P2Y12-inhibitors like prasugrel and ticagrelor, there still exists an early increase in ischemic events following primary PCI in patients with STEMI. Furthermore there is also an immediate increased risk of bleeding [4]. Although guidelines recommend as early administration as possible of P2Y12-inhibitors, clinical data

\footnotetext{
* Correspondence: sasha.koul@med.lu.se

'Department of Cardiology, Lund University, Skåne University Hospital Lund, SE 221 85, Lund, Sweden

Full list of author information is available at the end of the article
}

regarding the timing of P2Y12-inhibitor administration in STEMI patients is limited [5,6]. Neither prasugrel nor ticagrelor have any outcome data regarding effects of pretreatment in STEMI patients. Clopidogrel pre-treatment has in register studies and in the small randomized CIPAMI trial shown promise compared to no pre-treatment at all, however large randomized data do not exist [7-11]. Platelet inhibition data might give some insight into these questions, however pharmacodynamic data regarding prasugrel, ticagrelor and even clopidogrel in the acute phase of STEMI is also limited [12,13]. Pre-treatment protocols with other substances, including GPIIb/IIIa-inhibitors have been studied with mixed results on various efficacy endpoints [14-16]. 
The aim of this study was to evaluate the platelet inhibition of 5 different anti-platelet protocols in the acute phase of STEMI in patients undergoing primary PCI.

\section{Methods}

\section{Study design}

Patients undergoing PCI for STEMI at Skåne University Hospital in Lund were prospectively included in the Lund Platelet Registry from October 2009 to October 2012 (total $n=223$ ). All STEMI patients were eligible for inclusion. However if the patients had not received a P2Y12-inhibitor or primary PCI was not performed, they were excluded. Aspirin treatment was given as standard treatment unless contraindicated in the individual patient. Bivalirudin was used as first-line antithrombotic adjuvant therapy during PCI. Usage of GPIIb/ IIIa-inhibitors were used as bail-out option at the physician's discretion (Table 1). Platelet reactivity was measured serially using a flow cytometric assay for the vasodilatorstimulated phosphoprotein (VASP) at three time-points: a) After performed angiography prior to PCI (pre-PCI VASP) b) after completed PCI procedure (post-PCI VASP) and c) the following morning after PCI (day after VASP). A total of 5 different cohorts were included according to their P2Y12-inhibition (Figure 1). 1) At the time of initiation of the registry all patients were treated with upstream clopidogrel only (upstream clopidogrel group, $\mathrm{n}=75)$.

2) As the results of the TRITON trial were published prasugrel was incorporated into clinical practice as a bolus dose of prasugrel $(60 \mathrm{mg})$ in the catheterization laboratory on top of a previous bolus dose of upstream clopidogrel $(600 \mathrm{mg})$ in patients with no major risk factors for bleeding or other contraindications (upstream clopidogrel-prasugrel switch, $\mathrm{n}=97$ ). A weight below $60 \mathrm{~kg}$ or age above 75 years were not considered as contraindications for a bolus dose prasugrel, however maintenance therapy for these patients consisted of clopidogrel $75 \mathrm{mg}$ o.d. A history of stroke or TIA was considered an absolute contraindication for any use of prasugrel. Prasugrel was not used in a pre-hospital setting as it was not endorsed in either national or international guidelines as a pre-hospital drug at that time. 3) A subset of patients were only given prasugrel at the cath lab after performed coronary angiography (prasugrel cath lab group, $\mathrm{n}=11$ ). 4) As ticagrelor became available, patients were initially given a bolus dose of clopidogrel upstream $(600 \mathrm{mg})$ followed by a bolus dose of ticagrelor $(180 \mathrm{mg})$ in the catheterization laboratory (upstream clopidogrel-ticagrelor switch, $\mathrm{n}=10$ ) unless contraindicated. 5) As pre-hospital ticagrelor became

Table 1 Patient characteristics

\begin{tabular}{|c|c|c|c|c|c|c|}
\hline & $\begin{array}{l}\text { Upstream } \\
\text { clopidogrel } \\
(n=75)\end{array}$ & $\begin{array}{l}\text { Upstream clopidogrel-prasugrel } \\
\text { switch } \\
(\mathrm{n}=97)\end{array}$ & $\begin{array}{l}\text { Prasugrel } \\
\text { cath lab } \\
(\mathrm{n}=11)\end{array}$ & $\begin{array}{l}\text { Upstream clopidogrel-ticagrelor } \\
\text { switch } \\
(n=10)\end{array}$ & $\begin{array}{l}\text { Upstream } \\
\text { ticagrelor } \\
(n=30)\end{array}$ & $\begin{array}{l}P \text { - } \\
\text { value }\end{array}$ \\
\hline Age & $71 \mathrm{yrs}$ & 62 yrs & $61 \mathrm{yrs}$ & $64 \mathrm{yrs}$ & $65 \mathrm{yrs}$ & $<0.01$ \\
\hline Male sex & $53(71 \%)$ & 75 (77\%) & $8(73 \%)$ & $8(80 \%)$ & $20(67 \%)$ & 0.74 \\
\hline Smoking status & & & & & & $<0.01$ \\
\hline Never smoked & $29(39 \%)$ & $23(25 \%)$ & $4(36 \%)$ & $2(20 \%)$ & $5(17 \%)$ & \\
\hline Previous smoker & $28(37 \%)$ & $25(28 \%)$ & $0(0 \%)$ & $4(40 \%)$ & $6(20 \%)$ & \\
\hline Current smoker & $17(23 \%)$ & $43(47 \%)$ & $6(55 \%)$ & $4(40 \%)$ & $16(53 \%)$ & \\
\hline \multicolumn{7}{|l|}{$\begin{array}{l}\text { Adjuvant anti- thrombotic } \\
\text { treatment }\end{array}$} \\
\hline Aspirin & 74 (99\%) & $91(94 \%)$ & $11(100 \%)$ & $10(100 \%)$ & $30(100 \%)$ & 0.09 \\
\hline Heparin & $72(96 \%)$ & 90 (93\%) & $11(100 \%)$ & $10(100 \%)$ & $30(100 \%)$ & 0.39 \\
\hline Gpllb/llla-inhibitors & $5(6.7 \%)$ & $1(1.1 \%)$ & $1(9.1 \%)$ & $0(0 \%)$ & $0(0 \%)$ & 0.13 \\
\hline Bivalirudin & $70(93 \%)$ & 86 (89\%) & $11(100 \%)$ & $10(100 \%)$ & 30 (100\%) & 0.17 \\
\hline \multicolumn{7}{|l|}{ Prior diseases } \\
\hline Hypertension & $46(61 \%)$ & $28(31 \%)$ & $1(9.1 \%)$ & $2(20 \%)$ & 15 (50\%) & $<0.01$ \\
\hline Myocardial infarction & $15(20 \%)$ & $7(7.7 \%)$ & $1(9.1 \%)$ & $1(10 \%)$ & $3(10 \%)$ & 0.15 \\
\hline Diabetes & $6(8.0 \%)$ & $11(12 \%)$ & $0(0 \%)$ & $2(20 \%)$ & $5(17 \%)$ & 0.42 \\
\hline Previous CABG & $3(4.0 \%)$ & $0(0 \%)$ & $0(0 \%)$ & $0(0 \%)$ & $2(7 \%)$ & 0.17 \\
\hline Previous PCl & $9(12 \%)$ & $7(7.2 \%)$ & $0(0 \%)$ & $1(10 \%)$ & $4(13 \%)$ & 0.59 \\
\hline $\begin{array}{l}\text { Insertion of drug eluting } \\
\text { stent }\end{array}$ & $6(8 \%)$ & $10(10 \%)$ & $3(27 \%)$ & $0(0 \%)$ & 7 (23\%) & 0.06 \\
\hline
\end{tabular}

Gpllb/llla; Glycoprotein Ilb/Illa, CABG; Coronary Arterty Bypass Grafting, PCl; Percutaneous Coronary Intervention. 


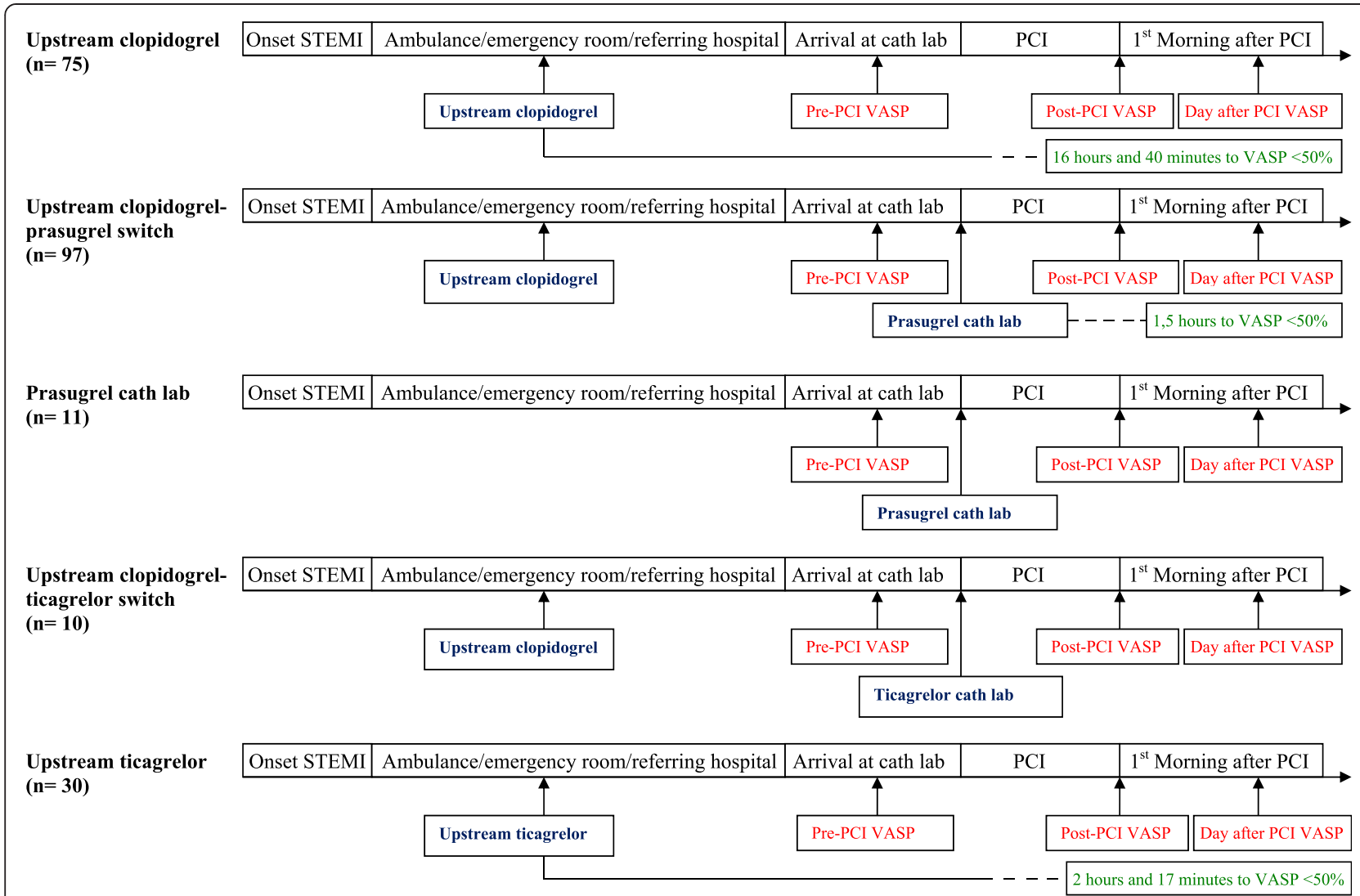

Figure 1 Clinical protocol. Flow-chart describing the 5 patient cohorts in the study and timings of blood sampling.

available in early 2012, patients were subsequently given ticagrelor mono-therapy $(180 \mathrm{mg})$ as an upstream bolus dose (upstream ticagrelor group, $\mathrm{n}=30$ ) unless contraindicated.

If patients were deemed not suitable for either prasugrel or ticagrelor they were per protocol given clopidogrel. A recommended treatment duration of at least one year of P2Y12-inhibition was recommended. Nearly all patients were given concomitant aspirin (Table 1).

\section{Patient data and clinical follow-up}

Patient data was primarily obtained from the Swedish Coronary Angiography and Angioplasty Registry (SCAAR) as well as through hospital patient records. The SCAAR registry includes data from all centres that perform coronary angiography or PCI in Sweden. Based on the unique Swedish 10-digit personal identification number, the SCAAR register was merged with other national registries, including the Swedish Hospital Discharge Registry and The Register of Information and Knowledge about Swedish Heart Intensive care Admissions (RIKS-HIA).

\section{VASP-analysis}

Platelet reactivity was measured using a commercially available flow cytometric assay of intraplatelet vasodilatorstimulated phosphoprotein (VASP), with analyses performed according to the manufacturer's instructions (Biocytex Platelet VASP kit, Marseille, FR) [17]. The platelet reactivity index (VASP-PRI) was calculated from the corrected mean fluorescence intensity (cMFI) following incubation of the platelets with either prostaglandin E1 alone or prostaglandin E1 with ADP using the formula:

$$
\begin{aligned}
\text { VASP-PRI } \%= & {[(\operatorname{cMFI}(\text { PGE1 })-\operatorname{cMFI}(\text { PGE1 }+ \text { ADP })) /} \\
& \operatorname{cMFI}(\text { PGE } 1)] \times 100 \%
\end{aligned}
$$

\section{Endpoints}

1. Percentage of patients reaching a VASP PRI-value of $<50 \%$ the day after PCI. The cut-off value for VASP-PRI was selected as a value above $50 \%$ has been associated with worse clinical outcomes following PCI [18].

2. Average time to reach a VASP PRI-value of $<50 \%$.

As safety parameter, major in-hospital bleeding events were recorded (fatal bleeding/cerebral bleeding/bleeding requiring surgery or transfusion. 


\section{Ethics}

The study protocol was in accordance with the Declaration of Helsinki. Patient informed consent and ethical approval was not needed as all blood sampling was part of routine coronary care and no blood samples were stored for further usage.

\section{Statistical methods}

Baseline characteristics were compared across the various patient groups using ANOVA for continuous parametric data and Pearson's chi-squared test for categorical data. Platelet reactivity as measured by continuous VASP PRIvalues was compared across time-points within treatment groups using ANOVA for parametric data and MannWhitney's $U$-test for non-parametric data. The equality of variances assumption was tested using Levene's test. The proportion of patients reaching a VASP PRI $<50 \%$ was compared using Pearson's chi-squared test. A p-value $<0.05$ was considered significant. The risk of major in-hospital bleeding was evaluated using the Kaplan-Meier estimator, with censoring at death or loss to follow-up. VASP sampling the day after PCI was performed on fixed times (between 05.00-06.00) but the time of the day during which PCI was performed varied (according to when then the patient arrived to the cath lab). Furthermore durations of PCI procedures varied, both factors allowing creation of time separation curves. These were created using linear regression models with VASP-PRI regressed on linear or log-transformed time, as appropriate from cluster plots. All analyses were performed using SPSS (SPSS version 18, SPSS Inc, Chicago).

\section{Results}

Patient characteristics are summarized in Table 1. Upstream clopidogrel patients were on an average older and had more comorbidities like hypertension and previous myocardial infarction than the other groups, in accordance with the clinical protocol where patients not deemed eligible for ticagrelor or prasugrel would receive clopidogrel. Anticoagulation with heparin and bivalirudin was often used during PCI procedures in the study. Nearly all patients received aspirin.

\section{Clopidogrel upstream group}

Patients in the clopidogrel upstream cohort had average VASP PRI-values of 74\% before PCI, 74\% after PCI and $56 \%$ the day after PCI, as shown in Table 2. The average VASP-PRI value the day after PCI was significantly lower than VAS-PRI values pre- and post-PCI $(\mathrm{p}<0.001)$. No statistically significant difference was noted between VASP PRI-values pre-PCI and post-PCI (Figure 2). A total of $32 \%$ in the clopidogrel upstream group reached a VASPPRI value of less than 50\% the day after PCI. In the clopidogrel upstream group time-separation curves showed a weak linear association between time and clopidogrel response (Figure 3) with a model coefficient of determination $\left(r^{2}\right)$ of 0.17 . An average time of 16.7 hours was noted between clopidogrel administration until a VASP-PRI value of $50 \%$ was reached according to the equation outlined in Figure 3. The rate of major in-hospital bleeding was $4 \%$.

\section{Prasugrel treated patient groups}

The average VASP-PRI values for the upstream clopidogrelprasugrel switch cohort were $79 \%$ before PCI, 74\% after PCI and $17 \%$ the day after PCI, as shown in Table 2 . A statistically significant reduction was noted between VASP-PRI values pre- and post-PCI $(\mathrm{p}=0.01)$ as well as between VASP PRI-values the day after PCI compared to pre- and post-PCI $(\mathrm{p}<0.001$, Figure 2$)$. A total of $90 \%$ of patients reached the pre-specified cutoff value of VASP-PRI $<50 \%$ the day after PCI ("good responders"). In time-separation curves for the upstream clopidogrel-prasugrel switch group (Figure 4), VASP-PRI appeared to follow an inversely logarithmic association with time, with an $\mathrm{r}^{2}$ of 0.66 . Derived from the equation outlined in Figure 4 the average time from prasugrel administration to a VASP PRI-value of $50 \%$ was 90 minutes. The rate of major in-hospital bleeding was $1.1 \%$ in this cohort.

The average VASP-PRI values for the prasugrel cath lab cohort were $80 \%, 69 \%$ and 19\%, as shown in Table 2 . A significant reduction in VASP-PRI values the day after PCI compared to pre- and post-PCI values was noted $(\mathrm{p}<0.01$, Figure 2). A trend towards a reduction in VASP-PRI values pre- and post-PCI was noted, however not achieving statistical significance $(p=0.24)$. A total of $91 \%$ of patients

Table 2 VASP-PRI data in the 5 treatment cohorts

\begin{tabular}{|c|c|c|c|c|c|}
\hline & $\begin{array}{l}\text { Upstream } \\
\text { clopidogrel }\end{array}$ & $\begin{array}{l}\text { Upstream clopidogrel-prasugrel } \\
\text { switch }\end{array}$ & $\begin{array}{l}\text { Prasugrel } \\
\text { cath lab }\end{array}$ & $\begin{array}{l}\text { Upstream clopidogrel-ticagrelor } \\
\text { switch }\end{array}$ & $\begin{array}{l}\text { Upstream } \\
\text { ticagrelor }\end{array}$ \\
\hline Pre-PCI VASP & $74 \%$ (SD 19) & 79\% (SD 13) & $80 \%$ (SD 15) & 79\% (SD 16) & $64 \%$ (SD 29) \\
\hline Post-PCI VASP & $74 \%$ (SD 20) & $74 \%$ (SD 21) & $69 \%$ (SD 34) & $77 \%$ (SD 20) & $53 \%$ (SD 30) \\
\hline Day after PCI VASP & $56 \%$ (SD 27) & $17 \%$ (SD 21) & 19\% (SD 18) & $15 \%(S D 8)$ & $29 \%(S D 25)$ \\
\hline $\begin{array}{l}\text { Percentage of patients } \\
\text { with VASP-PRI }<50 \% \text { day } \\
\text { after PCI }\end{array}$ & $32 \%$ & $90 \%$ & $91 \%$ & $100 \%$ & $83 \%$ \\
\hline
\end{tabular}




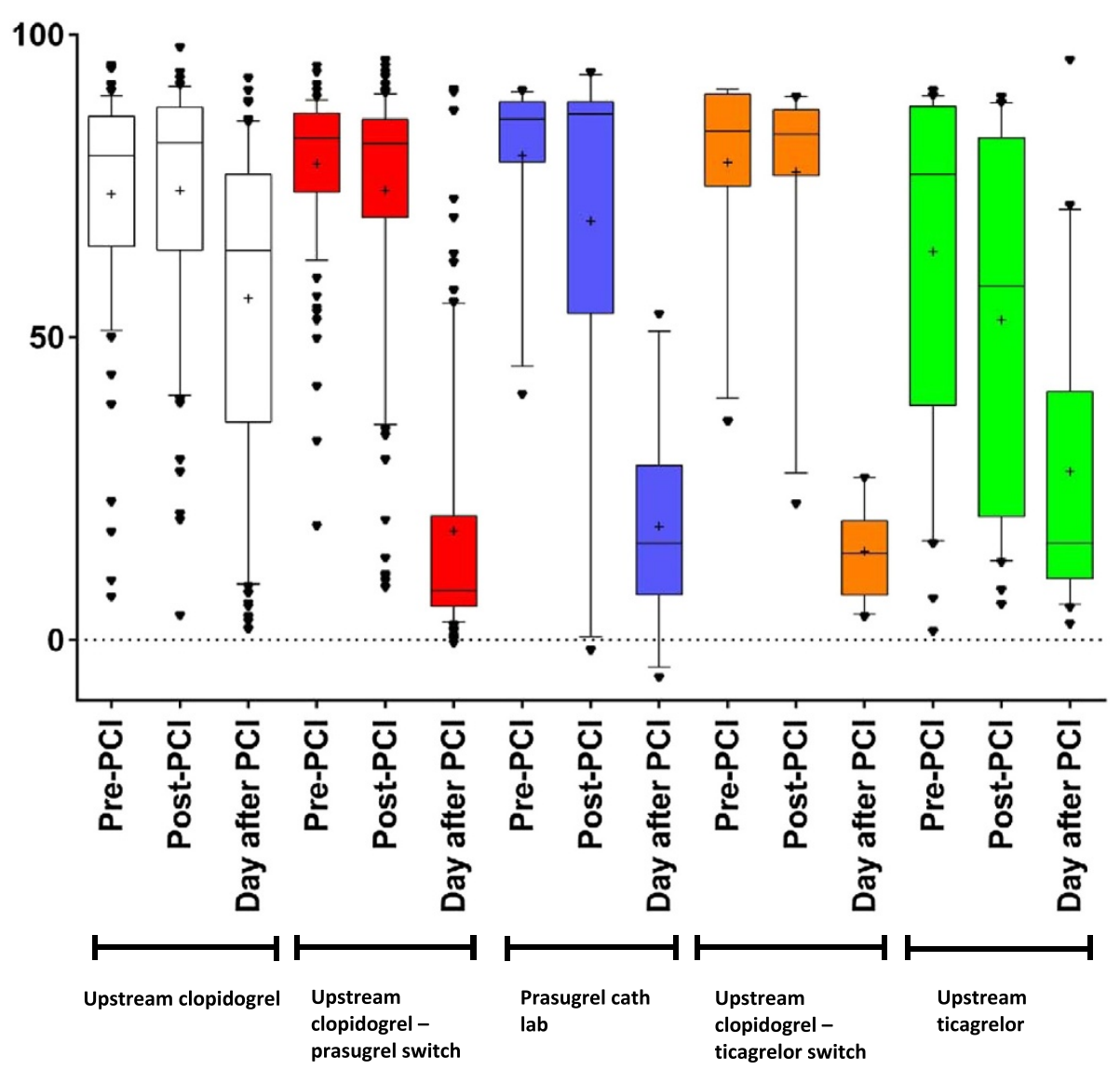

Figure 2 Average VASP-PRI values. Box-plot of median and average VASP-PRI values in the various patient cohorts (boxes denote median and 25-75 percentile and whiskers denote 10-90 percentile with outliers. Plus sign in boxes denotes the average value).

managed to reach the pre-specified cutoff value of VASP PRI $<50 \%$ the day after PCI. No patients experienced any major in-hospital bleedings. Too few values were obtained in the prasugrel cath lab group to allow a curve fit of adequate power.

\section{Ticagrelor treated patient groups}

The average VASP-PRI values for the upstream ticagrelor cohort were $64 \%$ before PCI, $53 \%$ after PCI and $29 \%$ the day after PCI, as shown in Table 2 . A statistically significant reduction was noted between VASP-PRI values pre- and post-PCI $(\mathrm{p}=0.01)$ as well as between VASP PRI-values the day after PCI compared to pre- and post-PCI $(\mathrm{p}<0.001$, Figure 2). A total of $83 \%$ of patients reached the prespecified cutoff value of VASP-PRI $<50 \%$ the day after PCI. In time-separation curves for the upstream ticagrelor group (Figure 5), VASP-PRI appeared, just as in upstream clopidogrel-prasugrel switch patients to follow an inversely logarithmic association with time, with an $\mathrm{r}^{2}$ of 0.32 . Derived from the equation outlined in Figure 5 the average time from ticagrelor administration to a VASP PRI-value of $50 \%$ was 2.2 hours in patients receiving upstream ticagrelor.
The rate of major in-hospital bleeding was 3.3\% in upstream ticagrelor treated patients.

In upstream clopidogrel-ticagrelor switch patients the average VASP PRI-values were 79\%, 77\% and 15\% (Table 2). No difference in VASP-PRI values were noted between pre- and post-PCI. A significant reduction was noted postPCI with all patients in this group being responders the day after PCI. No major in-hospital bleedings were noted for these patients. Too few values were obtained in the upstream clopidogrel-ticagrelor switch group to allow a curve fit of adequate power.

\section{Comparisons between treatment groups}

For VASP PRI-values pre-PCI, patients treated with upstream ticagrelor had numerically lower values compared to all other groups, but the difference was not statistically significant. Post-PCI the upstream ticagrelor group had statistically significantly lower VASP-PRI values compared to all other groups and $50 \%$ of upstream ticagrelor patients had achieved a VASP-PRI value of $<50 \%$ post-PCI. However the day after PCI, prasugrel patient groups showed lower VASP-PRI values compared to upstream 


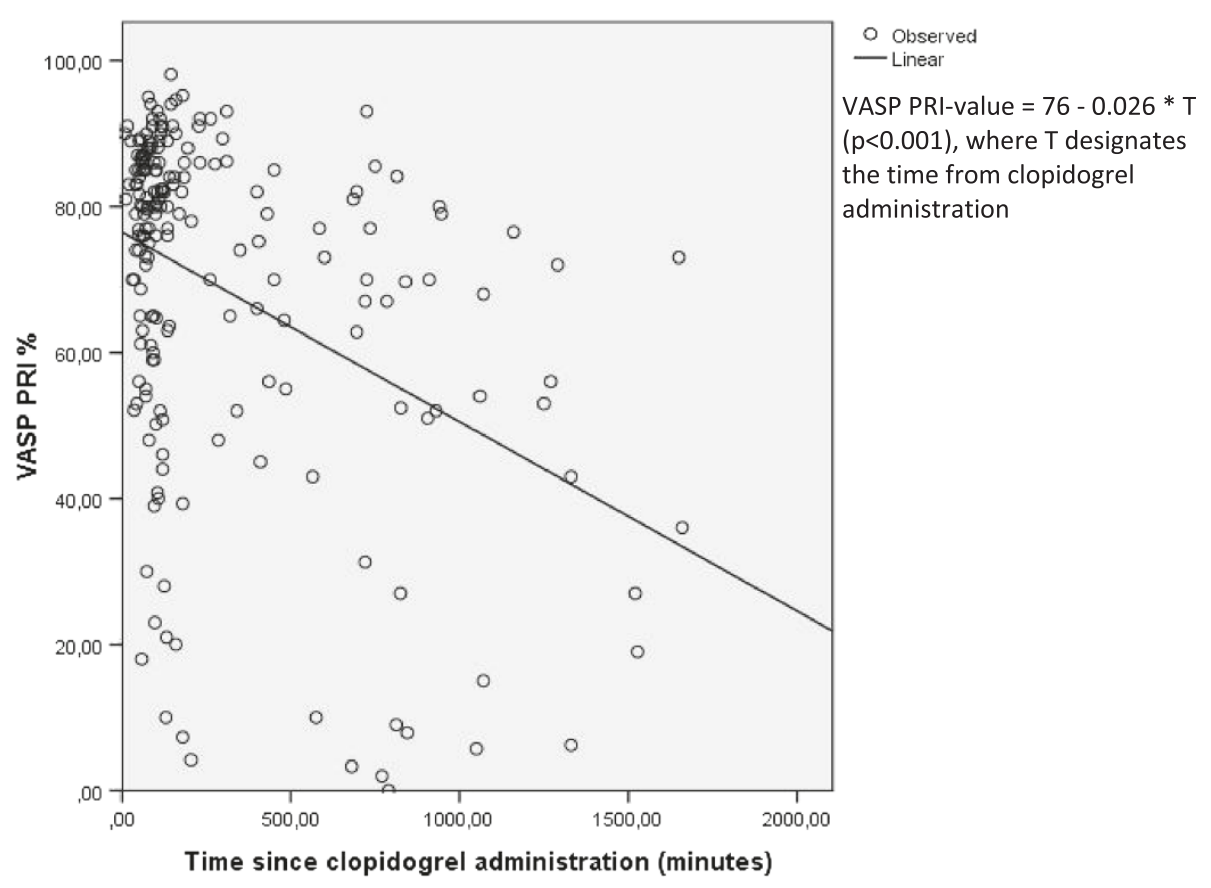

Figure 3 Regression curve upstream clopidogrel. VASP values as function of time in upstream clopidogrel patients with a linear regression plot.

ticagrelor as shown in Table 2. Between $83-100 \%$ of patients in the prasugrel or ticagrelor groups were responders the day after PCI, in comparison to $32 \%$ in the pre-hospital clopidogrel group ( $\mathrm{p}<0.001)$.

\section{Discussion}

The main findings of our study were:

1. In STEMI patients undergoing primary PCI and given upstream clopidogrel, a switch to prasugrel in the cath lab (after coronary angiography) led to similar rates of platelet inhibition the day after PCI as prasugrel mono-therapy given in the cath lab.

2. STEMI patients given ticagrelor or prasugrel had a high degree of platelet inhibition the day after PCI with rates between $80-100 \%$ of patients being good responders according to the high on treatment reactivity definition of VASP $<50 \%$. However patients given prasugrel showed a higher degree of platelet inhibition than patients given ticagrelor mono-therapy.

3. Patients given upstream treatment with a modern P2Y12-inhibitor (in our study only ticagrelor was used upstream) had in 50\% of cases adequate platelet inhibition at the time of PCI completion.

4. Time taken from prasugrel administration (on top of upstream clopidogrel) to an average VASP PRI-value of $<50 \%$ was 1.5 hours. Corresponding number for ticagrelor was 2.2 hours. Clopidogrel mono-therapy was associated with a slow and heterogeneous onset of action with an average of 16.7 hours from drug administration to a VASP PRI-value of $<50 \%$.

\section{Upstream clopidogrel patients}

Our study showed in the upstream clopidogrel group a markedly slow anti-platelet response, a finding shown in previous STEMI trials with clopidogrel [19]. A majority of patients did not achieve a VASP-PRI value of $<50 \%$ the day after PCI (Figure 2 and Table 2) and the mean time to reach $50 \%$ VASP-PRI was 16.7 hours. These results differ from more stable patient populations or in non-ST-elevation acute coronary syndromes where a $600 \mathrm{mg}$ loading dose of clopidogrel was associated with a more rapid, albeit slower than prasugrel, anti-platelet response [20-22]. This probably reflects (as mentioned previously) the physical stress that STEMI patients are exposed to [23]. Clopidogrel upstream patients showed in addition to a general slow-onset of action also significant heterogeneity in response with an overall weak linear response. Subsets of patients showed remarkable early effect, whereas other patients showed marked little response over time (Figure 3). These results are in accordance with our current state of knowledge of clopidogrel response, where patients due to several factors, both genetic as well acquired factors like diabetes, exhibit a high degree of variability in clopidogrel response, associated with different clinical outcomes [24]. 


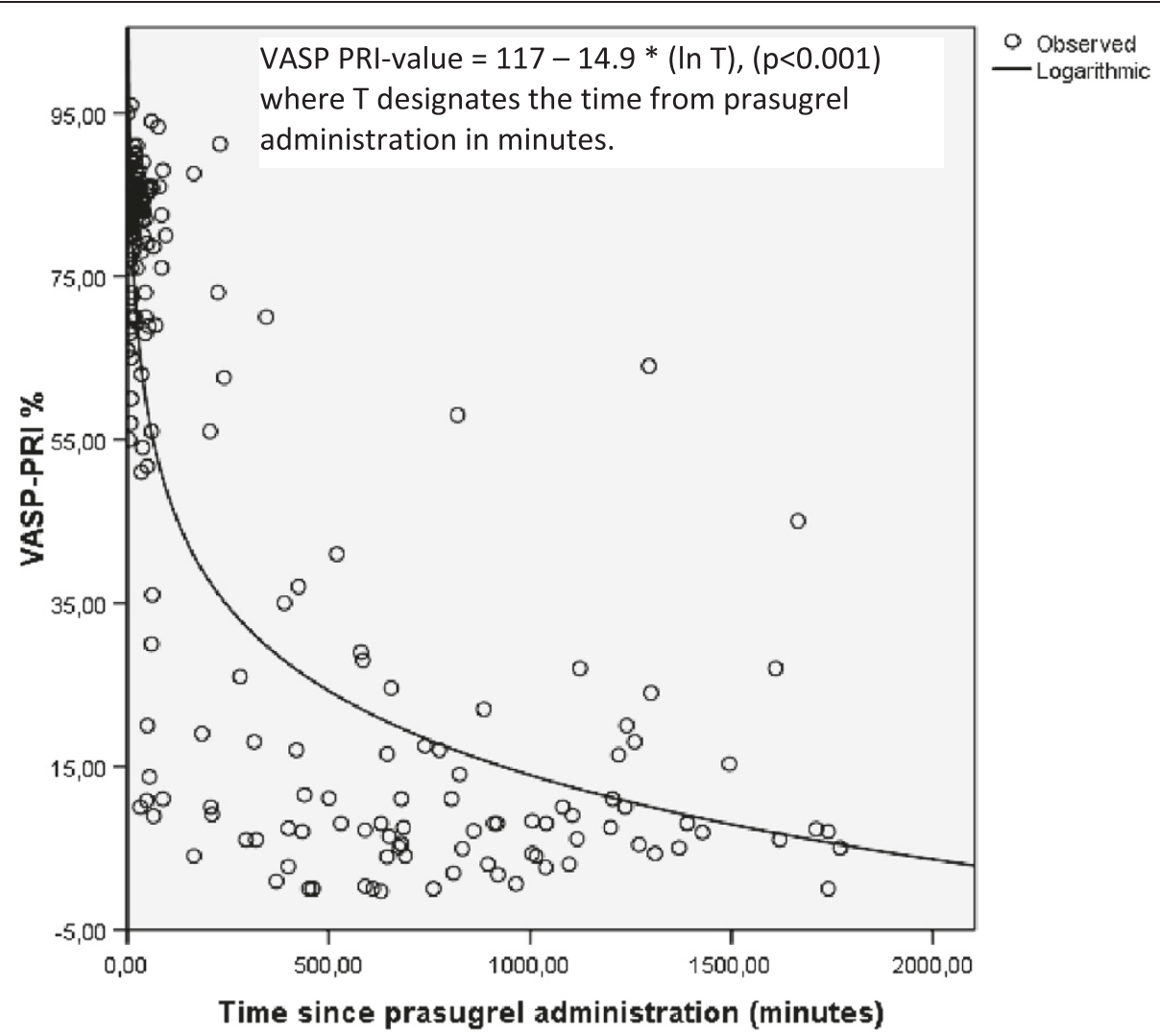

Figure 4 Regression curve upstream clopidogrel-prasugrel cath lab. VASP values as function of time in upstream clopidogrel-prasugrel cath lab patients with a logarithmic regression plot.

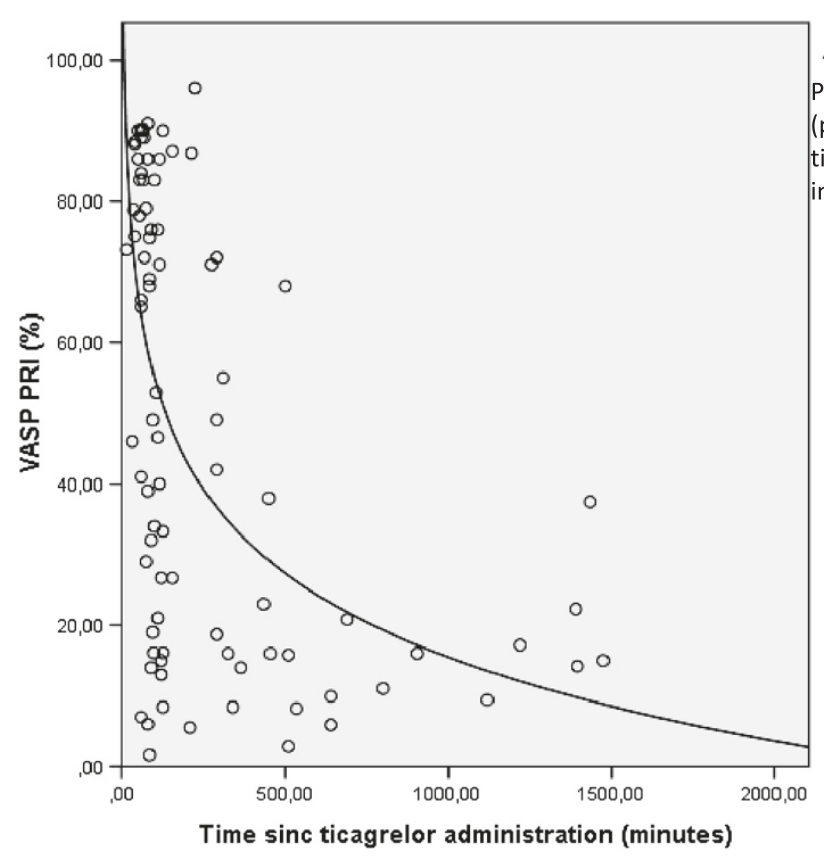

O Observed

PRI-value $=134-17.2 *(\ln \mathrm{T})$

$(p<0.001)$, where $T$ designates the time from ticagrelor administration

in minutes

Figure 5 Regression curve upstream ticagrelor. VASP values as function of time in upstream ticagrelor patients with a logarithmic regression plot. 


\section{Prasugrel treated patients}

Current guidelines suggest a loading dose of a P2Y12inhibitor as soon as possible in the setting of STEMI undergoing primary PCI $[5,25]$. In the TRITON trial, the vast majority of patients were included after a coronary angiogram was performed and no large published data exist regarding the clinical effects of upstream prasugrel treatment in STEMI patients [1]. Our study did not include prasugrel upstream since at the time of prasugrel introduction in Sweden this was not endorsed by either international or national guidelines. However our data indicated approximately 1.5 hours from prasugrel administration to a platelet "good responder" status in time separation curves. In previous studies in stable patients receiving prasugrel, approximate mean time to a $50 \%$ VASP-PRI value was only $30 \mathrm{~min}$ [22]. This constitutes a considerably faster onset than in our study and is probably explained by that STEMI patients are under formidable body stress, receive platelet inhibitors in supine position and are treated with opiates, all of which reduce gastrointestinal motility and uptake [19,23].

Our data further suggested that a treatment regimen of upstream clopidogrel followed by use of prasugrel after performed coronary angiogram led to a similar degree of platelet inhibition as if giving only prasugrel in the cath lab. No tendencies for too powerful anti-platelet effects or for attenuation of anti-platelet effect (as has been suggested for cangrelor) were noted compared to prasugrel mono-therapy [26]. Major in-hospital bleeding rate for this switch group was low (1.1\%). These data suggest that for patients who are given early clopidogrel, an additional bolus dose of prasugrel after coronary angiography is a pharmacodynamically feasible option making it possible to pre-treat all patients upstream with a low risk and then individualize treatment in cath lab dependening on risk-benefit ratio. This is of interest since in several countries neither prasugrel nor ticagrelor are available pre-hospitally but clopidogrel in general is. Furthermore addition of prasugrel in the cath lab led to improved platelet inhibition during $\mathrm{PCI}$, although in the majority of patients not reaching a VASP-PRI value of $<50 \%$ during PCI.

In a subgroup analysis of the TRITON trial, a significant and marked reduction in VASP PRI-value was noted for prasugrel 1-2 hours post loading dose compared to clopidogrel, results similar to ours. However the patients were not exclusively STEMI patients and dual treatment with clopidogrel and prasugrel was not reported [27]. In the FABOLUS PRO trial, prasugrel alone ( $\mathrm{n}=52$ for the prasugrel-only group) did not achieve sufficient levels of platelet inhibition during the first 2 hours in STEMI patients undergoing primary PCI. Since no further measurements were made until 6 hours post loading, the exact time point where prasugrel alone rendered sufficient degree of platelet inhibition was not known. Our results indicate a general faster onset of prasugrel and the differences could possibly be explained by usage of different techniques for measurement of platelet aggregation (light transmission aggregometry versus VASP) with different cut-off values for adequate degree of platelet inhibition [13]. Furthermore the majority of prasugrel patients in our study were pre-treated with clopidogrel compared to the FABOLUS PRO trial [13]. In a recent study $(n=27)$, data indicated that the majority of prasugrel patients were responders after 2 hours (between $65 \%-80 \%$ of patients depending on the method of measurement). These data are in accordance with our results [12]. However a second recent study $(\mathrm{n}=25)$ showed lower levels of responder rate at 2 hours (approximately 45\%) [28].

\section{Ticagrelor treated patients}

Our study showed that the time from upstream ticagrelor administration to an average VASP PRI-value of $<50 \%$ was 2.2 hours. Like prasugrel, this constitutes a significantly slower response compared to stable patients [29]. A previous study in STEMI patients $(\mathrm{n}=28$ for ticagrelor) demonstrated that a majority of ticagrelor patients were responders after 2 hours (54\%-68\% depending on the method of measurement), results close to ours [12]. However ticagrelor was only given in the catheterization laboratory in that study. In another recent study $(n=25)$, $40 \%$ of STEMI patients given ticagrelor (in the emergency room or in the cath lab) were responders after 2 hours, results close to ours [28]. Our study showed that if ticagrelor was given very early upstream (most patients given ticagrelor in the ambulance or referring hospital) 50\% were good responders at the completion of PCI (which corresponded to an average time of 2.2 hours after drug intake).

Switching from upstream clopidogrel to ticagrelor in the cath lab led to a lesser degree of platelet inhibition but well within the margin for "good responder status" compared to ticagrelor monotherapy. These data suggest, like in prasugrel treated patients, that switching from a low risk upstream option of clopidogrel followed by ticagrelor in cath lab depending on the results of the coronary angiography and after patient assessment is pharmacodynamically feasible. No major in-hospital bleeding was noted in the switch group.

\section{Limitations}

As registry study of three drugs with different contraindications and combinations, direct clinical comparisons were not performed due to the inherent risk of selection bias. Furthermore our study sample sizes for the prasugrel cath lab and the upstream clopidogrel-ticagrelor switch groups were limited in size. Interpretation of data 
from these groups should be done with caution. Bleeding was used as a safety end-point, but has to be interpreted with caution and due to non-randomized data with few events no comparisons in bleeding events between groups were made. Having a group with prasugrel given upstream would have yielded further information; however at the time of prasugrel introduction in Sweden, upstream prasugrel was not endorsed in either international or national Swedish guidelines since the vast majority of patients in the TRITON trial were given prasugrel only after coronary angiography (with high CABG bleeding rates for the prasugrel arm) [1].

\section{Conclusions}

In STEMI patients undergoing primary PCI, a switch to $60 \mathrm{mg}$ prasugrel in the cath lab on top of previous upstream clopidogrel $600 \mathrm{mg}(\mathrm{n}=97)$, led to similar rates of platelet inhibition as prasugrel mono-therapy $(\mathrm{n}=11)$ with a low in-hospital bleeding rate. Patients treated with prasugrel or ticagrelor demonstrated potent antiplatelet effects with $83-100 \%$ of patients being good responders the day after PCI compared to only $32 \%$ in patients receiving only clopidogrel. Upstream treatment with ticagrelor was associated with $50 \%$ of patients being good responders at the completion of PCI.

\section{Competing interests}

Sasha Koul and David Erlinge have received speaker fees from Eli Lilly and Astra Zeneca. Jan Harnek has received speaker fees from Astra Zeneca. The study was partly financed by an unrestricted grant from Eli Lilly.

\begin{abstract}
Authors' contributions
SK made substantial contributions to conception and design, acquisition of data, analysis and interpretation of data and was involved in drafting the manuscript. PA and AM were involved in acquisition of data, analysis and interpretation of data and in revising the paper for important intellectual content. JGS was involved in analysis and interpretation of data and in revising the paper for important intellectual content. FS was involved in conception and design, funding as well as revising the paper for important intellectual content. JH, MG, EN and SB were involved in acquisition of data, analysis and interpretation of data and in revising the paper for important intellectual content. DE made substantial contributions to conception and design, funding, analysis and interpretation of data and was involved in drafting the manuscript. All authors have read and approved the final manuscript.
\end{abstract}

\section{Funding}

This was an investigator initiated study where the costs for platelet measurements were partly financed by an unrestricted grant from Eli Lilly.

\section{Author details}

'Department of Cardiology, Lund University, Skåne University Hospital Lund, SE 221 85, Lund, Sweden. 'Department of Clinical Chemistry, Skåne University Hospital Malmö, Malmö, Sweden.

Received: 12 June 2014 Accepted: 11 December 2014 Published: 16 December 2014

\section{References}

1. Wiviott SD, Braunwald E, McCabe CH, Montalescot G, Ruzyllo W, Gottlieb S, Neumann FJ, Ardissino D, De Servi S, Murphy SA, Riesmeyer J, Weerakkody G, Gibson CM, Antman EM: Prasugrel versus clopidogrel in patients with acute coronary syndromes. N Engl J Med 2007, 357:2001-2015.
2. Montalescot G, Wiviott SD, Braunwald E, Murphy SA, Gibson CM, McCabe CH, Antman EM: Prasugrel compared with clopidogrel in patients undergoing percutaneous coronary intervention for ST-elevation myocardial infarction (TRITON-TIMI 38): double-blind, randomised controlled trial. Lancet 2009, 373:723-731.

3. Wallentin L, Becker RC, Budaj A, Cannon CP, Emanuelsson H, Held C, Horrow J, Husted S, James S, Katus H, Mahaffey KW, Scirica BM, Skene A, Steg PG, Storey RF, Harrington RA, Freij A, Thorsén M: Ticagrelor versus clopidogrel in patients with acute coronary syndromes. N Engl J Med 2009, 361:1045-1057.

4. Sibbing D, Steinhubl SR, Schulz S, Schomig A, Kastrati A: Platelet aggregation and its association with stent thrombosis and bleeding in clopidogreltreated patients: initial evidence of a therapeutic window. J Am Coll Cardiol 2010, 56:317-318.

5. Kushner FG, Hand M, Smith SC Jr, King SB 3rd, Anderson JL, Antman EM, Bailey SR, Bates ER, Blankenship JC, Casey DE Jr, Green LA, Hochman JS, Jacobs AK, Krumholz HM, Morrison DA, Ornato JP, Pearle DL, Peterson ED, Sloan MA, Whitlow PL, Williams DO: Focused Updates: ACC/AHA Guidelines for the Management of Patients With ST-Elevation Myocardial Infarction (updating the 2004 Guideline and 2007 Focused Update) and ACC/AHA/SCAI Guidelines on Percutaneous Coronary Intervention (updating the 2005 Guideline and 2007 Focused Update): a report of the American College of Cardiology Foundation/American Heart Association Task Force on Practice Guidelines. Circulation 2009, 120:2271-2306.

6. Steg PG, James SK, Atar D, Badano LP, Lundqvist CB, Borger MA, Di Mario C, Dickstein K, Ducrocq G, Fernandez-Aviles F, Gershlick AH, Giannuzzi P Halvorsen S, Huber K, Juni P, Kastrati A, Knuuti J, Lenzen MJ, Mahaffey KW Valgimigli M, Van't Hof A, Widimsky P, Zahger D: ESC Guidelines for the management of acute myocardial infarction in patients presenting with ST-segment elevation: The Task Force on the management of ST-segment elevation acute myocardial infarction of the European Society of Cardiology (ESC). Eur Heart J 2012, 33:2569-2619.

7. Koul S, Smith JG, Schersten F, James S, Lagerqvist B, Erlinge D: Effect of upstream clopidogrel treatment in patients with ST-segment elevation myocardial infarction undergoing primary percutaneous coronary intervention. Eur Heart J 2011, 32:2989-2997.

8. Larson DM, Duval S, Sharkey SS, Solie C, Tschautscher C, Lips DL, Burke MN Steinhubl S, Henry TD: Clopidogrel pretreatment in ST-elevation myocardial infarction patients transferred for percutaneous coronary Intervention. Am Heart J 2010, 160:202-207.

9. Matetzky S, Shenkman B, Guetta V, Shechter M, Bienart R, Goldenberg I, Novikov I, Pres H, Savion N, Varon D, Hod H: Clopidogrel resistance is associated with increased risk of recurrent atherothrombotic events in patients with acute myocardial infarction. Circulation 2004, 109:3171-3175.

10. Sabatine MS, Hamdalla HN, Mehta SR, Fox KA, Topol EJ, Steinhubl SR, Cannon CP: Efficacy and safety of clopidogrel pretreatment before percutaneous coronary intervention with and without glycoprotein Ilb/Illa inhibitor use. Am Heart J 2008, 155:910-917.

11. Vlaar PJ, Svilaas T, Damman K, de Smet BJ, Tijssen JG, Hillege HL, Zijlstra F: Impact of pretreatment with clopidogrel on initial patency and outcome in patients treated with primary percutaneous coronary intervention for ST-segment elevation myocardial infarction: a systematic review. Circulation 2008, 118:1828-1836.

12. Alexopoulos D, Xanthopoulou I, Gkizas V, Kassimis G, Theodoropoulos KC, Makris G, Koutsogiannis N, Damelou A, Tsigkas G, Davlouros P, Hahalis G: Randomized assessment of ticagrelor versus prasugrel antiplatelet effects in patients with ST elevation myocardial infarction. Circ Cardiovasc Interv 2012, 5:797-804.

13. Valgimigli M, Tebaldi M, Campo G, Gambetti S, Bristot L, Monti M, Parrinello G, Ferrari R: Prasugrel versus tirofiban bolus with or without short post-bolus infusion with or without concomitant prasugrel administration in patients with myocardial infarction undergoing coronary stenting: the FABOLUS PRO (Facilitation through Aggrastat By drOpping or shortening Infusion Line in patients with ST-segment elevation myocardial infarction compared to or on top of PRasugrel given at loading dOse) trial. JACC Cardiovasc Interv 2012, 5:268-277.

14. Prati F, Petronio S, Van Boven AJ, Tendera M, De Luca L, de Belder MA, Galassi AR, Imola F, Montalescot G, Peruga JZ, Barnathan ES, Ellis S, Savonitto S: Evaluation of infarct-related coronary artery patency and microcirculatory function after facilitated percutaneous primary coronary angioplasty: the FINESSE-ANGIO (Facilitated Intervention With Enhanced 
Reperfusion Speed to Stop Events-Angiographic) study. JACC CardiovasC Interv 2010, 3:1284-1291.

15. Mehilli J, Kastrati A, Schulz S, Frungel S, Nekolla SG, Moshage W, Dotzer F, Huber K, Pache J, Dirschinger J, Seyfarth M, Martinoff S, Schwaiger M, Schömig A: Abciximab in patients with acute ST-segment-elevation myocardial infarction undergoing primary percutaneous coronary intervention after clopidogrel loading: a randomized double-blind trial. Circulation 2009, 119:1933-1940.

16. Van't Hof AW, Ten Berg J, Heestermans T, Dill T, Funck RC, van Werkum W, Dambrink JH, Suryapranata H, van Houwelingen G, Ottervanger JP, Stella P Giannitsis E, Hamm C: Prehospital initiation of tirofiban in patients with ST-elevation myocardial infarction undergoing primary angioplasty (On-TIME 2): a multicentre, double-blind, randomised controlled trial. Lancet 2008, 372:537-546.

17. Aleil B, Ravanat C, Cazenave JP, Rochoux G, Heitz A, Gachet C: Flow cytometric analysis of intraplatelet VASP phosphorylation for the detection of clopidogrel resistance in patients with ischemic cardiovascular diseases. J Thromb Haemost 2005, 3:85-92.

18. Bonello L, Camoin-Jau L, Arques S, Boyer C, Panagides D, Wittenberg O, Simeoni MC, Barragan P, Dignat-George F, Paganelli F: Adjusted clopidogrel loading doses according to vasodilator-stimulated phosphoprotein phosphorylation index decrease rate of major adverse cardiovascular events in patients with clopidogrel resistance: a multicenter randomized prospective study. J Am Coll Cardiol 2008, 51:1404-1411.

19. Heestermans AA, van Werkum JW, Taubert D, Seesing TH, von Beckerath $N$, Hackeng CM, Schomig E, Verheugt FW, ten Berg JM: Impaired bioavailability of clopidogrel in patients with a ST-segment elevation myocardial infarction. Thromb Res 2008, 122:776-781.

20. Braun OO, Johnell M, Varenhorst C, James S, Brandt JT, Jakubowski JA, Winters KJ, Wallentin L, Erlinge D, Siegbahn A: Greater reduction of platelet activation markers and platelet-monocyte aggregates by prasugrel compared to clopidogrel in stable coronary artery disease. Thromb Haemost 2008, 100:626-633.

21. Payne CD, Li YG, Small DS, Ernest CS 2nd, Farid NA, Jakubowski JA, Brandt JT, Salazar DE, Winters KJ: Increased active metabolite formation explains the greater platelet inhibition with prasugrel compared to high-dose clopidogrel. J Cardiovasc Pharmacol 2007, 50:555-562.

22. Wallentin L, Varenhorst $C$, James $\mathrm{S}$, Erlinge $\mathrm{D}$, Braun $\mathrm{OO}$, Jakubowski JA, Sugidachi A, Winters KJ, Siegbahn A: Prasugrel achieves greater and faster P2Y12receptor-mediated platelet inhibition than clopidogrel due to more efficient generation of its active metabolite in aspirin-treated patients with coronary artery disease. Eur Heart J 2008, 29:21-30.

23. Osmancik P, Jirmar R, Hulikova K, Peroutka Z, Pompachova A, Motovska Z, Widimsky P: A comparison of the VASP index between patients with hemodynamically complicated and uncomplicated acute myocardial infarction. Catheter Cardiovasc Interv 2010, 75:158-166.

24. Angiolillo DJ, Badimon JJ, Saucedo JF, Frelinger AL, Michelson AD, Jakubowski JA, Zhu B, Ojeh CK, Baker BA, Effron MB: A pharmacodynamic comparison of prasugrel vs. high-dose clopidogrel in patients with type 2 diabetes mellitus and coronary artery disease: results of the Optimizing anti-Platelet Therapy In diabetes MellitUS (OPTIMUS)-3 Trial. Eur Heart $J$ 2011, 32:838-846.

25. Van de Werf F, Bax J, Betriu A, Blomstrom-Lundqvist C, Crea F, Falk V, Filippatos G, Fox K, Huber K, Kastrati A, Rosengren A, Steg PG, Tubaro M, Verheugt $F$, Weidinger $F$, Weis M: Management of acute myocardial infarction in patients presenting with persistent ST-segment elevation: the Task Force on the Management of ST-Segment Elevation Acute Myocardial Infarction of the European Society of Cardiology. Eur Heart J 2008, 29:2909-2945.

26. Steinhubl SR, Oh JJ, Oestreich JH, Ferraris S, Charnigo R, Akers WS: Transitioning patients from cangrelor to clopidogrel: pharmacodynamic evidence of a competitive effect. Thromb Res 2008, 121:527-534.

27. Michelson AD, Frelinger AL 3rd, Braunwald E, Downey WE, Angiolillo DJ, Xenopoulos NP, Jakubowski JA, Li Y, Murphy SA, Qin J, McCabe CH, Antman EM, Wiviott SD: Pharmacodynamic assessment of platelet inhibition by prasugrel vs. clopidogrel in the TRITON-TIMI 38 trial. Eur Heart J 2009, 30:1753-1763.

28. Parodi G, Valenti R, Bellandi B, Migliorini A, Marcucci R, Comito V, Carrabba N, Santini A, Gensini GF, Abbate R, Antoniucci D: Comparison of prasugrel and ticagrelor loading doses in ST-segment elevation myocardial infarction patients: RAPID (Rapid Activity of Platelet Inhibitor Drugs) primary PCI study. J Am Coll Cardiol 2013, 61:1601-1606.
29. Gurbel PA, Bliden KP, Butler K, Tantry US, Gesheff T, Wei C, Teng R, Antonino MJ, Patil SB, Karunakaran A, Kereiakes DJ, Parris C, Purdy D, Wilson V, Ledley GS, Storey RF: Randomized double-blind assessment of the ONSET and OFFSET of the antiplatelet effects of ticagrelor versus clopidogrel in patients with stable coronary artery disease: the ONSET/OFFSET study. Circulation 2009, 120:2577-2585.

doi:10.1186/1471-2261-14-189

Cite this article as: Koul et al:: A pharmacodynamic comparison of 5 anti-platelet protocols in patients with ST-elevation myocardial infarction undergoing primary PCI. BMC Cardiovascular Disorders 2014 14:189.

\section{Submit your next manuscript to BioMed Central and take full advantage of:}

- Convenient online submission

- Thorough peer review

- No space constraints or color figure charges

- Immediate publication on acceptance

- Inclusion in PubMed, CAS, Scopus and Google Scholar

- Research which is freely available for redistribution

Submit your manuscript at www.biomedcentral.com/submit
C Biomed Central 